\title{
PERANCANGAN SISTEM INFORMASI PENJUALAN PADA PT ROYAL AGUNG BERDIKARI
}

\author{
Deyana Excelina ${ }^{1}$, Puji Astuti ${ }^{2}$, Abdul Mufti ${ }^{3}$ \\ Program Studi Teknik Informatika, Fakultas Teknik dan Ilmu Komputer, \\ Universitas Indraprasta PGRI \\ Jalan Raya Tengah No.80,Kelurahan Gedong,Pasar Rebo,Jakarta Timur \\ deyanaexcelina2006@gmail.com ${ }^{1}$, Poetie12@gmail.com², a_mufti@yahoo.com ${ }^{3}$
}

\begin{abstract}
Abstrak
PT Royal Agung Berdikari adalah perusahaan yang bergerak dalam bidang penjualan mainan yang belum menggunakan sistem komputerisasi dalam hal penjualan sehingga rentan akan kesalahan dan ketidakakuratan pendataan barang yang mengakibatkan sering terlupakan akan barang habis sebelum diorder ulang. Tujuan dari penelitian ini adalah untuk membuat rancangan aplikasi dengan Java NetBeans yang dipergunakan untuk mengolah data penjualan yang dapat mempermudah para karyawan dalam mengolah data-data tersebut karena data-data tersebut tersimpan di database MySQL dengan rapih, teratur, serta aman. Hasil dari aplikasi yang dibangun ini dapat mempermudah karyawan dalam mengendallikan penjualan sehingga lebih efektif dan efisien. Metode Penelitian yang digunakan oleh peneliti adalah grounded research yaitu suatu metode penelitian yang mendasarkan diri kepada fakta dan menggunakan analisis perbandingan yang bertujuan mengadakan generalisasi empiris, menetapkan konsep-konsep, membuktikan teori dan mengembangkan teori ketika pengumpulan data dan analisis data berjalan pada waktu bersamaan.
\end{abstract}

Kata Kunci : Perancangan Sistem Informasi, Penjualan, Grounded Research

\begin{abstract}
PT Royal Agung Berdikari is a company engaged in the sale of toys that have not used a computerized system in terms of sales, so they are prone to errors and inaccuracies in item data collection which result in often being forgotten about goods before re-ordering.The purpose of this research is to design an application with Java NetBeans which is used to process sales data which can make it easier for employees to process these data because the data is stored in the MySQL database neatly, regularly, and safely. The results of this application built can make it easier for employees to control sales so that it is more effective and efficient. The research method used by researchers is grounded research that is a research method that is based on facts and uses comparative analysis that aims to make empirical generalizations, establish concepts, prove theories and develop theories when data collection and data analysis run at the same time.
\end{abstract}

Keywords: Information System Design, Sales, Grounded Reasearch

\section{PENDAHULUAN}

Pada saat ini sistem informasi sangat berpengaruh disegala bidang kehidupan baik dibidang politik, pendidikan maupun ekonomi, khususnya dibidang perdagangan. Tetapi, dalam kenyataan masih banyak ditemukan beberapa tempat usaha kecil maupun besar yang masih menerapkan metode manual dalam sistemnya. Sehingga menyulitkan dalam pengontrolan data dan pembuatan laporan kepada pemilik toko. Perancangan menggambarkan rencana umum suatu kegiatan rancangan proyek dan aktivitas-aktivitas khusus yaitu Teknik atau metode-metode dalam merancang sesutatu (Arif, 2016). Sistem adalah kumpulan dari sub sistem atau komponen apapun baik fisik ataupun non fisik yang saling berhubungan satu sama lain dan bekerja sama secara harmonis untuk mencapai suatu tujuan tertentu (Susanto, 2013). Sistem adalah sekelompok elemen-elemen yang terintegrasi dengan tujuan yang sama (Yakub, 2012). Informasi adalah sejumlah data yang sudah diolah atau proses melalui prosedur pengolahan data dalam rangka menguji tingkat kebenaranya, keterpakaiannya sesuai dengan kebutuhan (Darmawan, 2012). PT Royal Agung Berdikari adalah perusahaan yang bergerak dalam bidang penjualan mainan. Dalam memasuki dunia persaingan yang semakin ketat, pengusaha dituntut untuk dapat bersaing dalam segala hal termasuk dalam teknologi informasi yang diterapkan pada usaha tersebut. Dalam hal ini, penyusun ingin menerapkan dan mengubah teknik yang semula masih manual menjadi sistem yang terkomputerisasi pada perusahaan tersebut dalam pengolahan data supplier, pengolahan data barang, pengolahan pengadaan barang, dan pada keseluruhan transaksinya masih melakukan 
pencatatan manual dalam setiap transaksinya.dengan sistem tersebut bagian penjualan dan pengadaan barang sering mengalami kekurangan.

Penelitian yang dilakukan di PT Royal Agung Berdikari bertujuan untuk mengumpulkan data-data yang dibutuhkan untuk keperluan analisis sistem informasi penjualan. Data-data ini akan membantu tujuan-tujuan penelitian selanjutnya. Diantaranya, untuk membuat aplikasi perancangan sistem informasi penjualan pada PT Royal Agung Berdikari dengan harapan PT Royal Agung Berdikari dapat meningkatkan fungsinya sebagai penjual mainan. Dengan sistem penjualan ini dapat terkomputerisasi dan dapat memberi kemudahan kepada karyawan tersebut.

Netbeans adalah sebuah aplikasi IDE (Integrated Development Environment) open source yang sering kali diasosiasikan dengan Java. Akan tetapi, bila diperhatikan IDE yang satu ini tidak hanya digunakan sebagai IDE untuk membuat program java saja, melainkan juga program seperti web service (Nishom, 2012). Java adalah bahasa pemrograman yang terkenal. Java banyak digunakan untuk membangun program, dirilis pertama kali pada tahun 1995 oleh Sun Microsystems. Penciptanya adalah James Gosling (Kadir, 2012). Aplikasi ini juga menggunakan database MySQL. Database adalah susunan record data operasional lengkap dari satu organisasi atau perusahaan yang diorganisir dan disimpan secara terintegrasi dengan menggunakan metode tertentu dalam komputer sehingga mampu memenuhi informasi yang optimal yang dibutuhkan oleh pengguna (Kristanto, 2010). MySQL adalah sebuah perangkat lunak sistem manajemen basis data SQL (database management system) atau DBMS yang multithread, multi-user, dengan sekitar 6 juta instalasi di seluruh dunia. MySQL AB membuat $M y S Q L$ tersedia sebagai perangkat lunak gratis dibawah lisensi GNU General Public License (GPL), tetapi mereka juga menjual dibawah lisensi komersial untuk kasus-kasus dimana penggunaannya tidak cocok dengan penggunaan GPL (Masria, 2012). Dan juga menggunakan perangkat pendukung lainnya seperti Xampp. XAMPP adalah perangkat lunak gratis yang mendukung banyak sistem operasi dan merupakan kompilasi dari beberapa program (Ginting, 2013).

Sedangkan manfaat yang diharapkan akan diperoleh dari penelitian ini adalah dengan penggunaan sistem informasi penjualan akan sangat membantu perusahaan dalam sistem pengolahan data penjualan dan transaksi penjualan yang lebih efektif dan efisien.

\section{PENELITIAN RELEVAN}

Penelitian relevan merupakan penelitian terdahulu atau sebelumnya yang relevan dengan konsep penelitian sehingga menjadi acuan atau dasar mengembangkan suatu hasil penelitian sebelumnya. Berikut peneliti mengambil sumber dari beberapa penelitian dari jurnal yang berjudul Perancangan Sistem Aplikasi Penjualan Sparepart Pada Toko Kim Jaya Motor (Marsudi et al., 2020). Dengan hasil data yang dikumpulkan dapat disimpulkan menggunakan sistem terkomputerisasi maka Toko Kim Jaya Motor akan mengalami peningkatan dalam menangani proses seluruh data terutama data penjualan dibandingkan dengan sistem manual. Yang kedua penelitian yang berjudul Perancangan Sistem Informasi Penjualan VOUCHER GAME ONLINE Berbasis Dekstop pada AREN.NET di Depok (Ananditya et al., 2020). Proses transaksi penjualan voucher menjadi efektif karena di sistem ini sudah otomatis tersedia voucher dan stok voucher. Proses transaksi sudah terkomputerisasi, sehingga dapat mempermudah dan mempercepat waktu pekerjaan dalam pengolahan dan penjualan voucher.

\section{METODE PENELITIAN}

Metode penelitian yang digunakan peneliti adalah metode grounded (Grounded Research) yaitu suatu metode penelitian yang mendasarkan diri kepada fakta dan menggunakan analisis perbandingan yang bertujuan mengadakan generalisasi empiris, menetapkan konsep-konsep, membuktikan teori dan mengembangkan teori ketika pengumpulan data dan analisis data berjalan pada waktu bersamaan (Prastowo, 2011). Dalam penelitian ini data merupakan sumber teori atau teori berdasarkan data. Mengolah dan menganalisa data membangun hipotesis menjadi teori serta menulis draft laporannya dari waktu ke waktu. Setelah melakukan pengumpulan data peneliti melanjutkan proses penelitian sesuai dengan langkah-langkah pokok yang digunakan pada metode 
ini, yaitu menentukan masalah yang ingin diselidiki, mengumpulkan masalah yang ditemukan serta membuat laporan hasil penelitian.

a. Survei

Survei ini dilakukan mengamati secara langsung proses yang digunakan oleh PT Royal Agung Berdikari

b. Studi Pustaka

Studi pustaka dilakukan dengan mencari informasi atau data melalui buku-buku, artikel dan internet sebagai referensi yang berkaitan dengan penelitian.

c. Studi Lapangan

Studi lapangan merupakan metode untuk memperoleh data yang ada pada saat penelitian. Metode studi lapangan ini peneliti lakukan untuk melihat langsung terhadap penerapan sisem penjualan yang ada pada PT Royal Agung Berdikari. Dalam studi lapangan ini digunakan teknik wawancara. Teknik pengumpulan data ini dilakukan dengan cara bertanya langsung (wawancara).teknik pengumpulan data ini dilakukan dengan bertanya langsung pada manager PT Royal Agung Berdikari yang bernama Bapak Ahan mengenai bagaimana sistem penjualan dan bagaimana prosedur penjualan di PTRoyal Agung Berdikari dengan tujuan agar mengerti perancangan yang selama ini dipakai. Diharapkan dari metode ini dapat diketahui kendalakendala yang dialami pada tempat tersebut.

d. Analisis Perancangan

1. Analisa Kebutuhan Sistem, Dalam tahapan perancangan sistem informasi sangat perlu menggunakan analisa kebutuhan, dapat berguna untuk memperoleh data-data yang akan digunakan sebagai inputan sistem informasi dari pengolahan data penjualan.

2. Perancangan sistem informasi merupakan pengembangan sistem baru dari sistem lama yang telah ada, dimana masalah-masalah yang ada pada sistem yang lama diharapkan dapat teratasi pada sistem yang baru dan dapat diimplementasikan dengan kebutuhan pengguna.

3. Desain Aplikasi, pada tahap ini akan dilakukan perancangan struktur data, karakteristik antarmuka, dan tampilan layar dari sistem yang akan dirancang agar menarik dan juga menghibur.

4. Pengkodean dan pengujian sistem, Sebelum sistem dijalankan maka harus melaksanakan pembuatan " PERANCANGAN SISTEM INFORMASI PENJUALAN PADA PTROYAL AGUNG BERDIKARI" dengan perintah kode program. Setelah proses pengkodean selesai maka akan dilakukan proses pengujian terhadap program yang dirancang untuk mengetahui apakah program sudah berjalan dengan benar dan baik sesuai dengan desain yang dilakukan sebelumnya.

5. Implementasi dan evaluasi, implementasi dilakukan untuk memsatikan apakah semua sistem berjalan dengan baik, dan apakah ada kesalahan pada sistem. Implementasi atau pengujian amat sangat penting dilakukan untuk menjadi peninjau akhir terhadap spesifikasi, desain serta pengkodean. Proses evaluasi dilakukan melalui testing aplikasi untuk mengecek jika terdapat error yang bisa menghentikan program secara tiba-tiba ataupun terdapat fungsi-fungsi yang tidak berjalan sesuia dengan apa yang telah ditentukan.

6. Tahap Penelitian laporan. tahap ini dilakukan pengolahan, analisa, dan pembahasan hasil penelitian serta kesimpulan dari hasil penelitian yang telah dilakukan selama masa penelitian.

\section{HASIL DAN PEMBAHASAN}

Pada diagram nol ini terdapat entity yaitu supplier, konsumen, staf toko, marketing dan pemilik toko. Terdapat 6 proses yaitu : input datasupplier, input data barang, pengadaan barang, penjualan, retur barang dan laporan. Adapun gambar diagram nol dapat dilihat pada gambar berikut : 


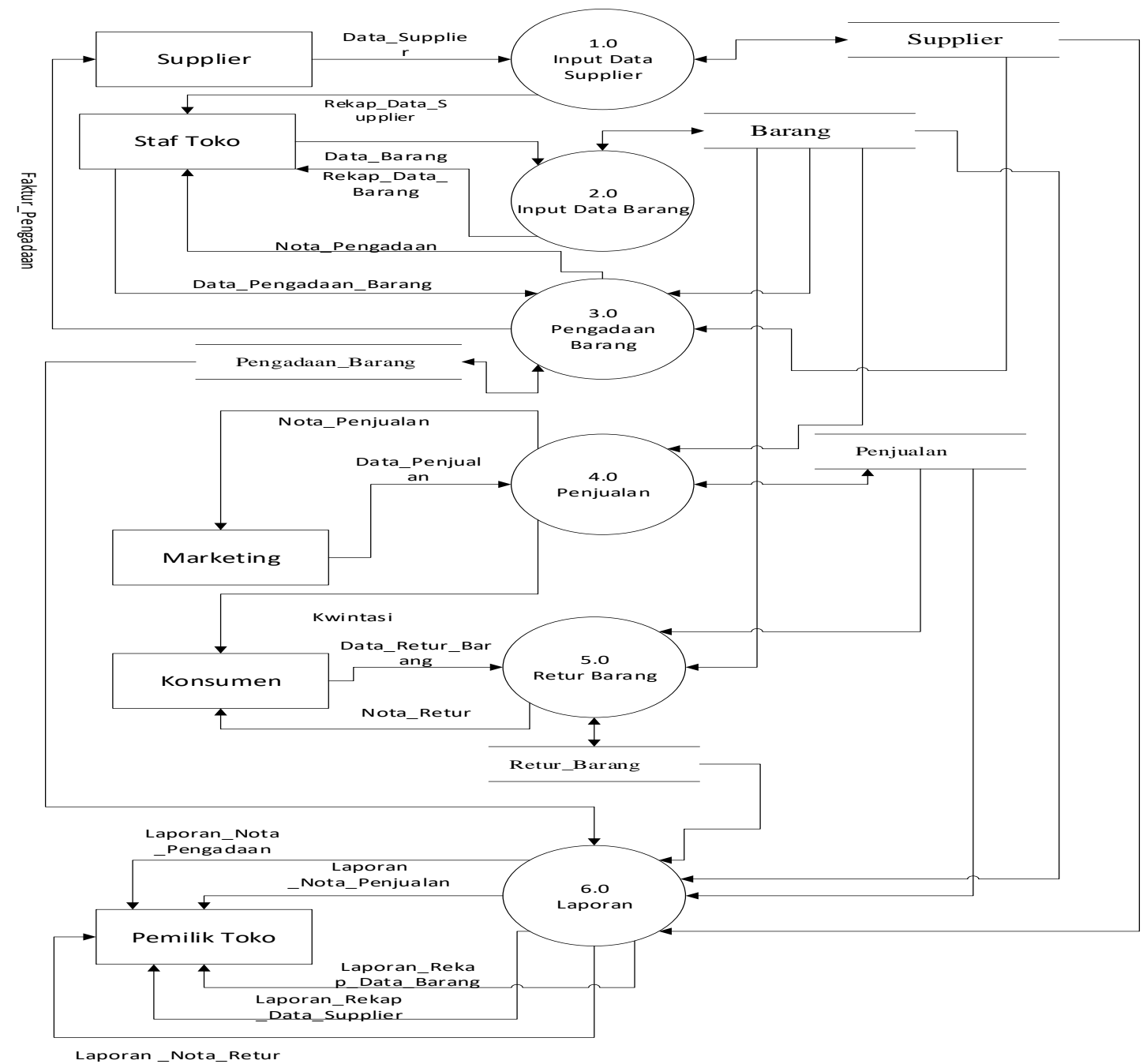

Gambar 1. Diagram nol Sistem yang di Usulkan

Didalam dekomposisi fungsi ini terdapat data supplier, data barang, pengadaan barang, penjualan, retur barang dan laporan.

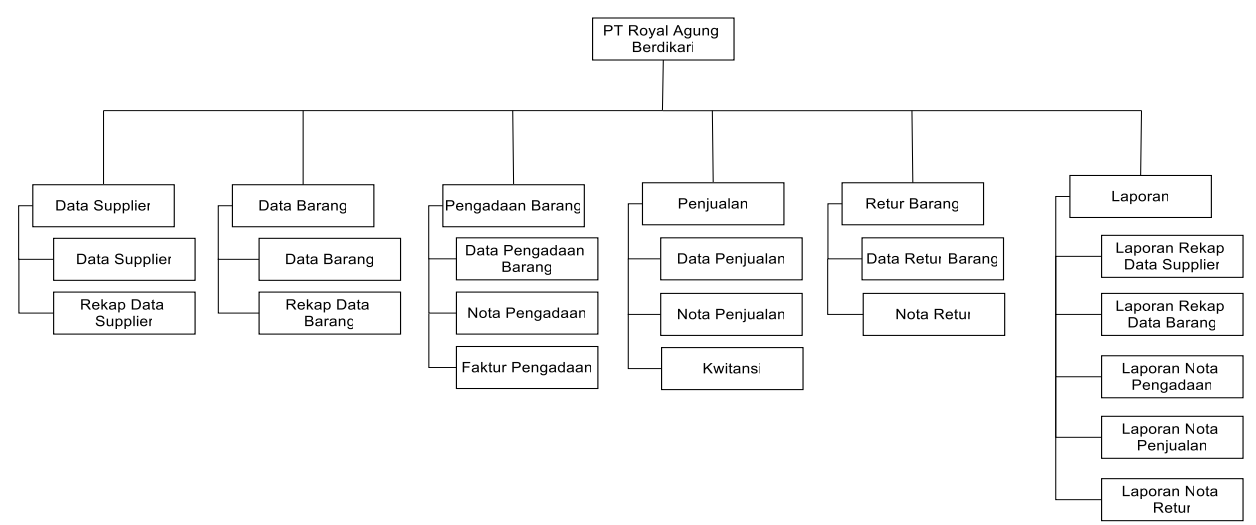

Gambar 2. Dekomposisi Fungsi

Proses selanjutnya peneliti membuat aplikasi ini dengan menggunakan java netbeans edisi 8.2 berbasis desktop dan menggunakan basisdata $M y S Q L$. 
Dibawah ini adalah tampilan dari aplikasi penjualan pada PT Royal Agung Berdikari

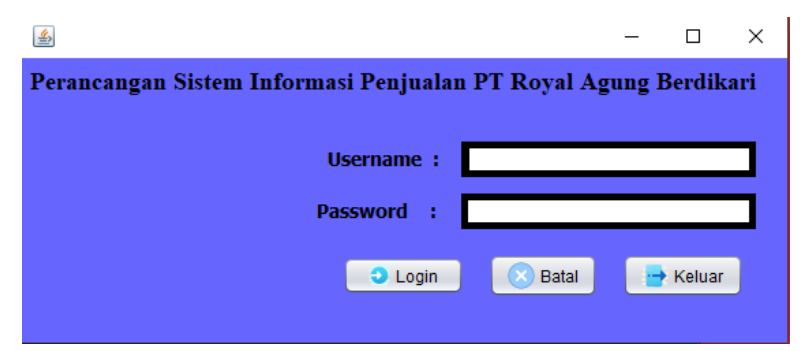

Gambar 3. Tampilan Menu Login

Tampilan ini terdapat pada awal program. Menu login digunakan sebagai kata kunci sebelum pengguna menggunakan program. Akses pada sistem ini diberikan kepada karyawan. Tidak sembarangan orang dapat masuk ke sistem ini. Hal ini dimaksudkan agar sistem dan data tetap terjaga dengan baik.

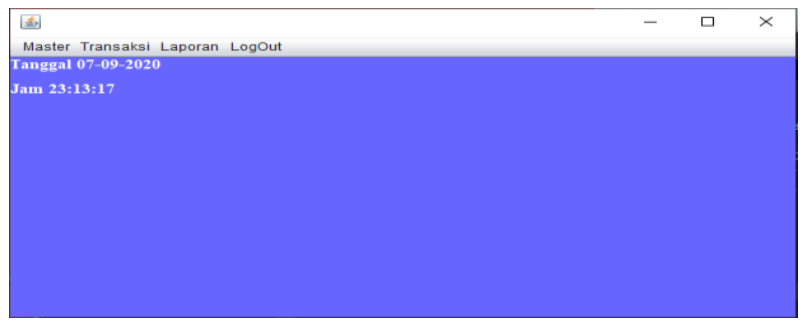

Gambar 4. Tampilan Menu Utama

Layar di atas tampilan menu utama perancangan penjualan. Pada layar menu utama tersedia menu bar yang terdiri dari master, transaksi, laporan dan logout. Menu master terdapat data supplier dan data barang. Menu transaksi terdapat pengadaan barang, penjualan dan retur barang. Menu laporan terdapat laporan rekap data supplier, laporan rekap data barang, laporan nota pengadaan barang, laporan nota penjualan dan laporan nota retur. Sedangkan menu logout untuk keluar dari program.

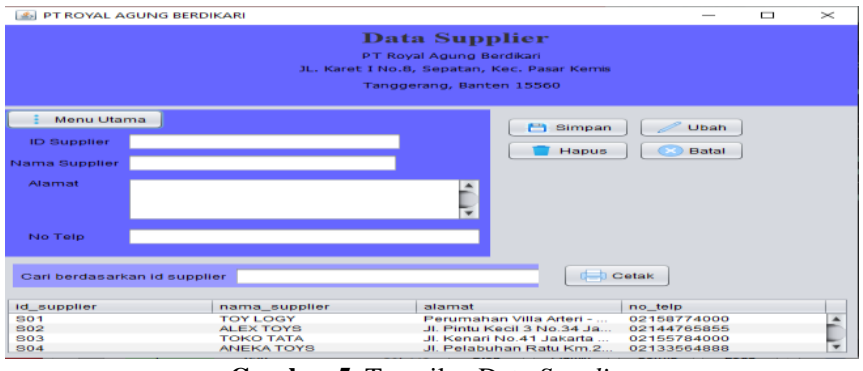

Gambar 5. Tampilan Data Supplier

Tampilan input data supplier berisikan id supplier, nama supplier, alamat, no telp. Terdapat tombol simpan untuk menyimpan data, ubah untuk mengubah data, hapus untuk menghapus data batal untuk membatalkan mengetik data, cetak untuk cetak laporan dan menu utama untuk kembali ke menu utama.

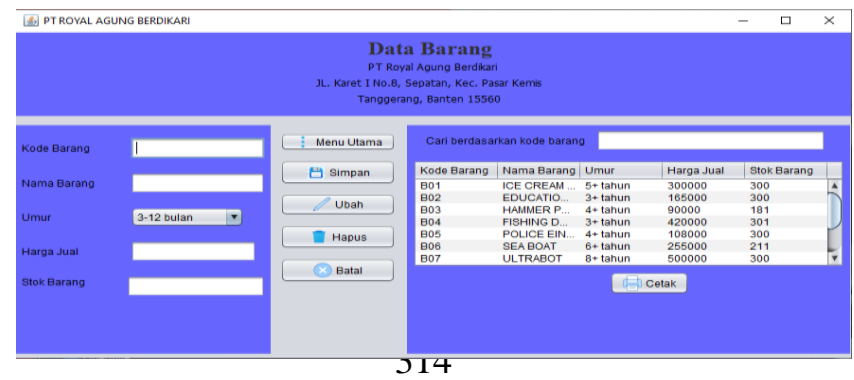


Gambar 6. Tampilan Data Barang

Tampilan input data barang berisikan kode barang, nama barang, umur, harga jual dan stok barang. Terdapat tombol simpan untuk menyimpan data, ubah untuk mengubah data, hapus untuk menghapus data batal untuk membatalkan mengetik data, cetak untuk cetak laporan dan menu utama untuk kembali ke menu utama.

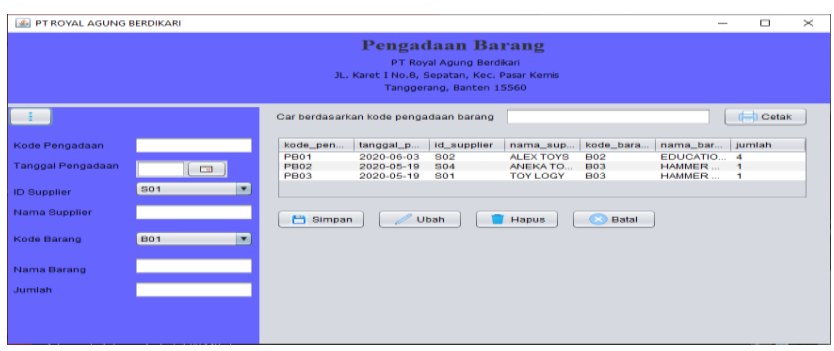

Gambar 7. Tampilan Pengadaan Barang

Tampilan input pengadaan barang berisikan kode pengadaan, tanggal pengadaan, id supplier, nama supplier, kode barang, nama barang, jumlah. Terdapat tombol simpan untuk menyimpan data, ubah untuk mengubah data, hapus untuk menghapus data batal untuk membatalkan mengetik data, cetak untuk cetak laporan dan menu utama untuk kembali ke menu utama.

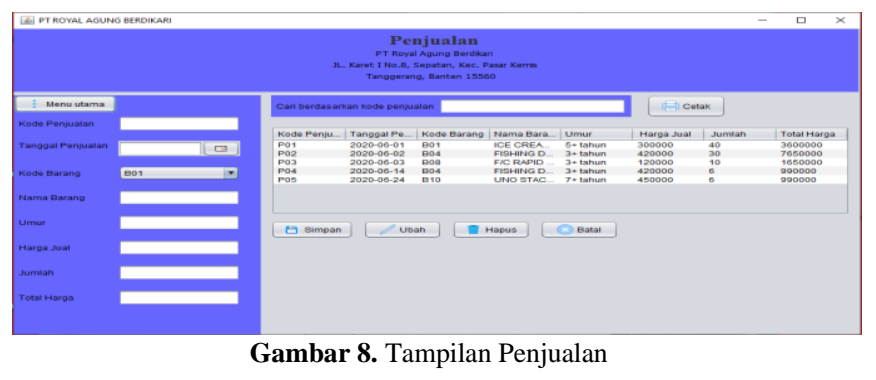

Tampilan input penjualan berisikan kode penjualan, tanggal penjualan, kode barang, nama barang, umur, harga jual, jumlah dan total harga. Terdapat tombol simpan untuk menyimpan data, ubah untuk mengubah data, hapus untuk menghapus data batal untuk membatalkan mengetik data, cetak untuk cetak laporan dan menu utama untuk kembali ke menu utama.

Tampilan ini adalah tampilan output dari program diatas

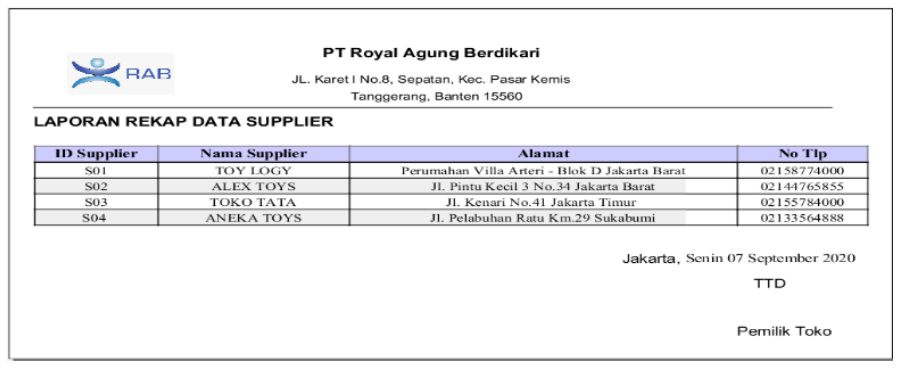

Gambar 9. Tampilan Laporan Rekap Data Supplier

Layar ini berfungsi untuk mengetahui berapa banyak data supplier yang berisikan id supplier, nama supplier, alamat dan no telp. Diinput oleh staf toko dan diberikan ke pemilik toko. 


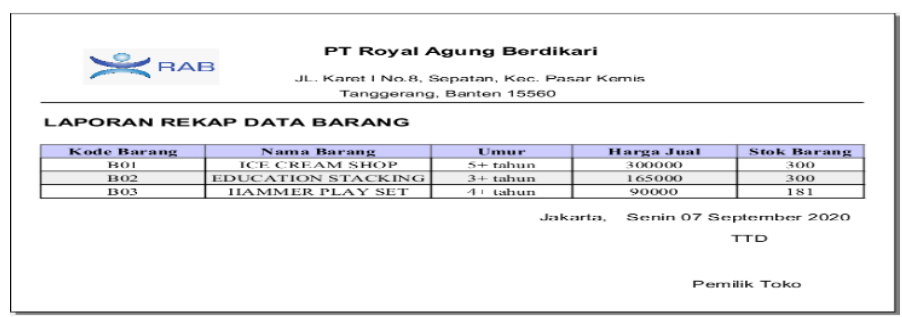

Gambar 10. Tampilan Laporan Rekap Data Barang

Layar ini berfungsi untuk mengetahui berapa banyak data barang yang berisikan kode barang, nama barang, umur, harga jual dan stok barang. Diinput oleh staf toko dan diberikan ke pemilik toko.

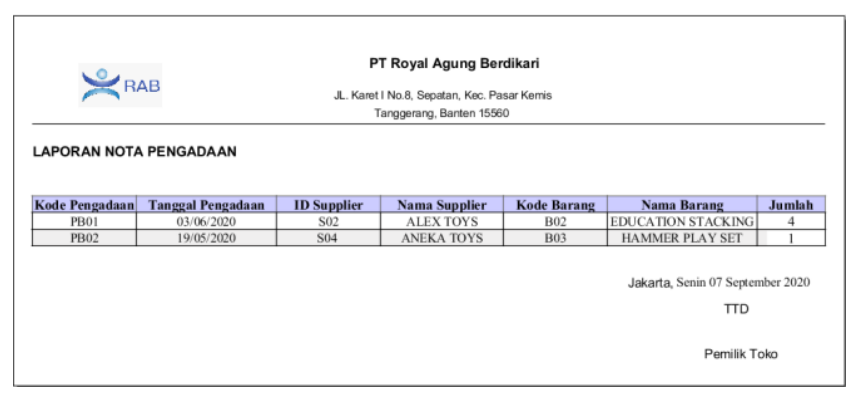

Gambar 11. Tampilan Laporan Nota Pengadaan

Layar ini berfungsi untuk mengetahui berapa banyak barang yang habis dan meminta agar supplier mengirimkan barang yang dibutuhkan. Berisikan kode pengadaan, tanggal pengadaan, id supplier, nama supplier, kode barang, nama barang, dan jumlah. Diinput oleh staf toko dan diberikan ke pemilik toko.

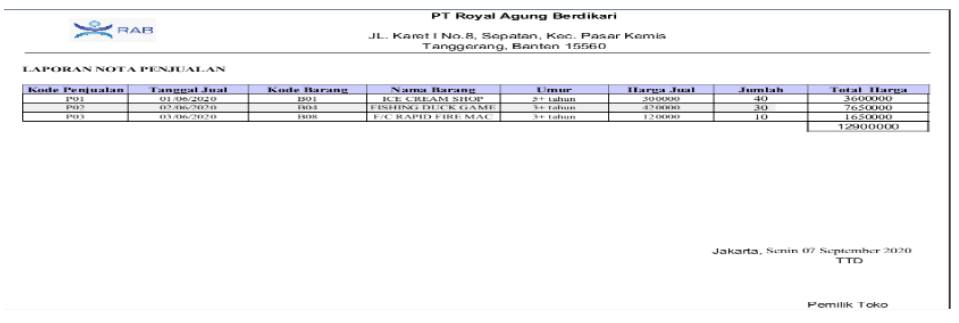

Gambar 12. Tampilan Laporan Nota Penjualan

Layar ini berfungsi untuk mengetahui berapa banyak barang yang sudah terjual. Berisikan kode penjualan, tanggal penjualan, kode barang, nama barang, umur, harga jual, jumlah dan total harga. Diinput oleh staf toko dan diberikan ke pemilik toko. 


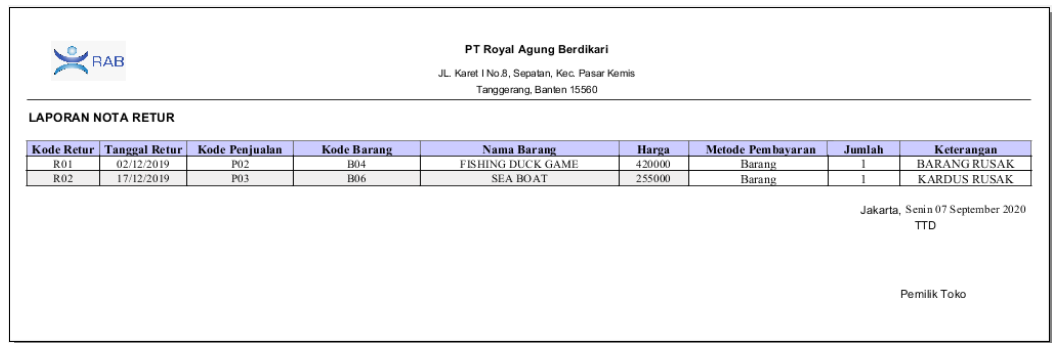

Gambar 13. Tampilan Laporan Nota Retur

Layar ini berfungsi untuk mengetahui berapa banyak yang meretur barang data. Berisikan kode retur, tanggal retur, kode penjualan, kode barang, nama barang, harga dan metode pembyaran, jumlah dan keterangan. Diinput oleh staf toko dan diberikan ke pemilik toko.

\section{SIMPULAN}

Dengan dibuatnya aplikasi Perancangan Sistem Informasi Penjualan Pada PT Royal Agung Berdikari semua kegiatan yang berhubungan dengan pengolahan data penjualan dapat berjalan dengan baik dan lancar. Pada aplikasi ini, dapat menangani pekerjaan penginputan data-data penjualan dengan cepat dann akurat serta dapat di update dengan mudah.

\section{DAFTAR PUSTAKA}

Ananditya, A., Sriyono, S., \& Yanti, S. (2020). Perancangan Sistem Informasi Penjualan Voucher Game Online Berbasis Desktop pada Aren. Net di Depok. Jurnal Riset Dan Aplikasi Mahasiswa Informatika (JRAMI), 1(01).

Arif, M. (2016). Bahan Ajar Rancangan Teknik Industri. Deepublish.

Darmawan, D. (2012). Pendidikan teknologi informasi dan komunikasi: teori dan aplikasi. PT Remaja Rosdakarya. Ginting, E. (2013). Aplikasi Penjualan Berbasis Web (E-Commerce) Menggunakan Joomla Pada Mutiara Fashion. Kadir, A. (2012). Algoritma dan pemrograman menggunakan Java. Yogyakarta: Andi.

Kristanto, A. (2010). Kupas Tuntas PHP \& MySQL. Klaten: Cable Book.

Marsudi, D., Mufti, A., \& Lestari, M. (2020). Perancangan Sistem Aplikasi Penjualan Sparepart pada Toko Kim Jaya Motor. Jurnal Riset Dan Aplikasi Mahasiswa Informatika (JRAMI), 1(03).

Masria. (2012). Perakitan Komputer. Jakara : Lentera Printing.

Nishom, M. (2012). Pengertian Netbeans. Retrieved February, 5, 2014.

Prastowo, A. (2011). Metode penelitian kualitatif dalam perspektif rancangan penelitian. Yogyakarta: Ar-ruzz media. Susanto, A. (2018). Sistem Informasi Akuntansi.

Yakub, J. B. (2012). Pengantar Sistem Informasi. Graha Ilmu. 